\title{
LA PREVALENCIA DEL DERECHO DE IDENTIDAD DEL NIÑO, NIÑA Y ADOLESCENTE ANTE LA CADUCIDAD DE LA IMPUGNACIÓN DE PATERNIDAD
}

\author{
The Right PREVAlence Of IDENTITY OF the CHILD, GIRL AND teENAGER Before \\ THE EXPIRATION OF THE PATERNITY CHALLENGE
}

Fiorela Amaro Cosquillo* Universidad Peruana Los Andes

\section{Resumen}

Partiendo de un estudio del derecho nacional e internacional, la autora enfoca su análisis en las implicancias del plazo de caducidad dispuesto por el artículo 400 del Código Civil y logra identificar las consecuencias de seguir manteniendo vigente dicho término para el ejercicio del derecho de acción y el consecuente inicio del proceso judicial para la impugnación de la paternidad.

Palabras clave: Impugnación de paternidad; caducidad; control difuso; derecho a la verdad; relación paterno filial; derecho a la identidad.

\begin{abstract}
Based on a study of national and international law, the author focuses its analysis on the implications of the expiration period provided by article 400 of the Civil Code, identifying the consequences of keeping that term for the exercise of the action right and the consequent initiation of the judicial process for the challenge of paternity.
\end{abstract}

Keywords: Challenge of paternity; expiration; diffuse control; right to the truth; filial parental relationship; right to identity.

Bachiller en Derecho y Ciencias Políticas por la Universidad Peruana Los Andes. Asistente Judicial de la Segunda Sala Laboral Permanente de la Corte Superior de Justicia de Junín. 


\section{EL DERECHO A LA IDENTIDAD DEL NIÑO, NIÑA O ADOLESCENTE}

El derecho a la identidad es un derecho fundamental muy importante para la persona, pues, a través de éste, cada ser humano se individualiza del resto, es decir, es único desde su nacimiento hasta su muerte, por lo que es importante no solo afirmarse como persona sino como «una cierta persona». Sin embargo, este derecho puede verse mellado por diversas causas, como por la acción de elementos falsos o verdaderos, que afectan de tal forma que la identidad resulta ser falseada, alterada, frente a la sociedad y la individualidad personal del mismo sujeto. En tal sentido, el Estado asume el deber de su protección.

Como el objeto de estudio del presente trabajo es la prevalencia del derecho a la identidad del niño, niña o adolescente, consideramos que entre las materias que regulan el derecho de familia, la filiación y su impugnación ha sido probablemente la que más tensiones de tipo constitucional ha planteado, cuando se afecta el derecho a la identidad de un niño, niña o adolescente por preferir la aplicación de una normal meramente legal.

La Constitución Politica del Perú de 1993 regula en el inciso 1 de su artículo 2 que «[ $\mathrm{t}$ ]oda persona tiene derecho: 1 . A la vida, a su identidad, a su integridad moral, psíquica y física y a su libre desarrollo y bienestar. El concebido es sujeto de derecho en todo cuanto le favorece.» Ahora bien, el numeral 201 del artículo 2 del mismo texto normativo indica que «[t]oda persona tiene derecho a una nacionalidad».

Ahora bien, respecto al derecho a la identidad del niño, niña o adolescente, los artículos 7 y 8 de la Convención Internacional sobre los Derechos del Niño prescriben que el niño será inscrito inmediatamente después de su nacimiento y tendrá derecho desde que nace a un nombre, a adquirir una nacionalidad y, en la medida de lo posible, a conocer a sus padres y a ser cuidado por ellos. Así también que los Estados Partes velarán por la aplicación de estos derechos de conformidad con su legislación nacional y las obligaciones que hayan contraído en virtud de los instrumentos internacionales pertinentes en esta esfera, sobre todo cuando el niño resultara de otro modo apátrida. Asimismo, su artículo 8 determina el derecho del niño a preservar su identidad y a beneficiarse de la asistencia del Estado para que la misma sea protegida o, cuando sea necesario, 
restablecida. Ahora bien, de conformidad al artículo 6 del Código de los Niños y Adolescentes «[e]l niño y el adolescente tienen derecho a la identidad, lo que incluye el derecho a tener un nombre, a adquirir una nacionalidad y, en la medida de lo posible, a conocer a sus padres y llevar sus apellidos. Tienen también derecho al desarrollo integral de su personalidad». Así, Fernández manifiesta

que el derecho a la identidad es el conjunto de atributos y características que permiten individualizar a la persona en sociedad. Identidad personal es todo aquello que hace que cada cual sea "uno mismo» y no "otro». Este plexo de características de la personalidad de "cada cual» se proyecta hacia el mundo exterior, se fenomenaliza, y permite a los demás conocer a la persona, a cierta persona, en su «mismidad», en lo que ella es en cuanto específico ser humano (2015, p. 116).

En consonancia De Cupis A., citado por Fernández (2015), sostiene que:

La identidad personal es "ser uno mismo", representado con sus propios caracteres y por sus propias acciones, «constituyendo la misma verdad de la persona». Ella no puede, en sí y por sí, ser destruida, ya que la verdad, precisamente por ser la verdad, no puede ser eliminada (P. 110).

Así, el derecho a la identidad como derecho humano se fundamenta en el reconocimiento jurídico y social de una persona como sujeto de derechos y responsabilidades y, a su vez, de su pertenencia a un Estado, un territorio, una sociedad y una familia, condición necesaria para preservar la dignidad individual y colectiva de las personas, entonces el reconocimiento del derecho a la identidad, mediante el registro de nacimiento, permite al niño o niña o adolescente adquirir una identidad, un nombre y una nacionalidad. Asimismo, implica su incorporación como sujeto de derechos dentro de un Estado y su acceso a un conjunto de derechos humanos reconocidos internacionalmente (Dirección General de Compilación y Consulta del Orden Jurídico Nacional, 2011, p. 15). En el transcurso del crecimiento del niño, niña o adolescente, conforme a Doglioti, citado por Fernández (2015, p. 113), las características que concurren a formar la personalidad son las experiencias pasadas, la condición presente y, sobre todo, las posiciones, las aspiraciones y convicciones ideológicas, políticas y morales de cada individuo, por lo que el derecho a la identidad personal reclama la exigencia de ser reconocido socialmente como uno mismo, en la perspectiva de una cumplida representación de la personalidad individual en todos sus aspectos e implicaciones, en sus calidades y atribuciones. 


\subsection{Componentes del derecho a la identidad}

El derecho a la identidad puede adoptar dos formas, conforme al desarrollo de etapas del niño, niña y adolescente, estos son: la identidad estática y la dinámica.

El cariz estático, según Vargas (2011), citando a Fernández, es una identidad conformada por características que no varían en el tiempo, tales como el nombre, el sexo, la nacionalidad, el idioma de origen, el grado de parentesco (p. 111). Agrega Tommasini, citado por Fernández, que «el individuo se distingue de los otros seres humanos por una serie de signos externos, como el nombre, los datos respecto del nacimiento, la filiación, la imagen, todo lo cual constituye los perfiles estáticos concernientes a la "identificación”. Ellos están destinados, sustancialmente, a no cambiar» (Fernández 2015, p. 114).

\section{EL DECURSO PRESCRIPTORIO}

Sobre los hechos — entre ellos el tiempo- que tienen que suceder, así como las condiciones que deben cumplirse para invocar este beneficio legal, importa dar cuenta de los siguientes: inicio del decurso prescriptorio y la caducidad.

\subsection{Inicio del decurso prescriptorio}

$\mathrm{Al}$ respecto, $\mathrm{Vidal}$ señala que

[e]l inicio del decurso prescriptorio tiene lugar desde que la acción puede ejercitarse, esto es, desde que la pretensión del titular del derecho subjetivo pueda ser planteada a un órgano jurisdiccional en su exigibilidad. Así lo establece el art. 1993 del Código Civil que mantiene el principio romanista de la actio nata, según el cual actioni nondun natae non praescribitur (Vidal, 2011, p. 93).

\subsection{La caducidad}

Vidal (2011) refiere que la caducidad es una institución jurídica que se rige por el decurso del tiempo, es decir que si el sujeto no ejerce un determinado derecho señalado por ley, en el plazo que éste prevea, se extinguirá la acción y el derecho (pp. 171,172). Asimismo, Hinostroza (2002) señala que

la caducidad se funda en el orden público y en él seguridad jurídica, siendo 
factor primordial de aquella el plazo establecido legalmente para los casos en que en el derecho opera la caducidad. [...] A través de la caducidad se pretende dar firmeza o carácter definitivo a un determinado asunto que interesa al derecho. (p. 355)

Agrega el mismo autor que «los plazos de caducidad son disímiles y son fijados por el ordenamiento jurídico de manera abstracta, es decir, para generalidad de casos, sino que se establecen específicamente para cada situación que el legislador ha estimado susceptible de caducidad». (p. 365)».

\section{CONTROL DIFUSO}

El segundo párrafo del artículo 138 de la Constitución Política del Estado reconoce la supremacía de la Carta Magna sobre cualquier otra norma, permitiendo a los jueces la aplicación del control difuso, por medio del cual se convierte a los órganos jurisdiccionales en los principales controladores de la legalidad constitucional, debiendo aplicarse dicha facultad sólo cuando existe un conflicto real y concreto de intereses en el que debe discernirse la compatibilidad o incompatibilidad constitucional de una norma inferior. Así también, el artículo 14 de la Ley Orgánica del Poder Judicial establece que cuando los magistrados, al momento de fallar el fondo de la cuestión de su competencia en cualquier clase de proceso o especialidad, encuentren que hay incompatibilidad en la interpretación de una disposición constitucional y una con rango de ley, resuelven la causa con arreglo a la primera, debiendo las sentencias así expedidas ser elevadas en consulta a la Sala de Derecho Constitucional y Social Permanente de la Corte Suprema, norma que debe concordarse con el artículo 408, inciso 3, del Código Procesal Civil.

El control difuso de constitucionalidad, en su sentido original, significa la obligación de todo juez de mantener la observancia de la supremacía constitucional. A diferencia del control concentrado, el difuso se limita a la inaplicación de aquella norma que se presuma como contraria al orden constitucional, reservándose la facultad de declaración de inconstitucional, es decir, la expulsión de la norma del sistema jurídico a un órgano jurisdiccional supremo como el Tribunal constitucional (Ferrer, Martínez \& Figueroa, 2014, pp. 958, 959). 
En cuanto a la inexorable aplicación del control difuso, consideramos que en el caso materia de análisis se ve en la necesidad de aplicar el control difuso por ser relevante para resolver los conflictos de impugnación de paternidad, pues el artículo 400 del Código Civil no tiene una interpretación conforme a la Constitución Política contraviniendo el derecho a la identidad, así como el derecho a la verdad y a la familia. El control difuso que se debe efectuar se realizará conforme con los criterios establecidos en la sentencia recaída en el Expediente N. ${ }^{\circ}$ 02132-2008-PA/TC [caso Martínez García].

\section{LA PROTECCIÓN DEL INTERÉS SUPERIOR DEL NIÑO, NIÑA Y ADOLESCENTE COMO CONTENIDO CONSTITUCIONAL}

El principio constitucional de protección del interés superior del niño, niña y adolescente constituye un contenido constitucional implícito del artículo 4 de la Norma Fundamental en cuanto establece que «[l]a comunidad y el Estado protegen especialmente al niño, al adolescente, [...]». Tal contenido de fundamentalidad es reconocido a su vez por la Convención sobre los Derechos del Niño de 1989, aprobada por la Asamblea General de las Naciones Unidas el 20 de noviembre de 1989 y ratificada por el Estado Peruano, mediante Resolución Legislativa N.o 25278 del 3 de agosto de 1990, publicada en el diario oficial El Peruano el 4 de agosto de 1990. El texto de la mencionada Convención se publicó en Separata Especial el 22 noviembre 1990, y, mediante Ley N.o 25302, publicada el 4 de enero de 1991, se declaró de preferente interés nacional la difusión de la Convención sobre los Derechos del Niño.

La mencionada Convención sobre los Derechos del Niño establece —entre otras disposiciones_ las siguientes:

«Artículo 3

1. En todas las medidas concernientes a los niños que tomen las instituciones públicas o privadas de bienestar social, los tribunales, las autoridades administrativas o los órganos legislativos, una consideración primordial a que se atenderá será el interés superior del niño.

2. Los Estados Partes se comprometen a asegurar al niño la protección y el cuidado que sean necesarios para su bienestar, teniendo en cuenta los derechos y deberes de sus padres, tutores u otras personas responsables de él ante la ley y, con ese fin, tomarán todas las medidas legislativas y administrativas adecuadas.» 
«Artículo 27

1. Los Estados Partes reconocen el derecho de todo niño a un nivel de vida adecuado para su desarrollo físico, mental, espiritual, moral y social.

2. A los padres u otras personas encargadas del niño les incumbe la responsabilidad primordial de proporcionar, dentro de sus posibilidades y medios económicos, las condiciones de vida que sean necesarias para el desarrollo del niño.

$[\ldots]$

4. Los Estados Partes tomarán todas las medidas apropiadas para asegurar el pago de la pensión alimenticia por parte de los padres u otras personas que tengan la responsabilidad financiera por el niño. [...]»

Teniendo en cuenta que el artículo 55 de la Constitución establece que "[l] os tratados celebrados por el Estado y en vigor forman parte del derecho nacional», y que la Cuarta Disposición Final y Transitoria de la Constitución prescribe que "[l]as normas relativas a los derechos y a las libertades que la Constitución reconoce se interpretan de conformidad con la Declaración Universal de Derechos Humanos y con los tratados y acuerdos internacionales sobre las mismas materias ratificados por el Perú». No queda sino convenir en que los contenidos de la Convención sobre los Derechos del Niño resultan vinculantes en el ordenamiento jurídico peruano.

En ese contexto, el principio constitucional de protección del interés superior del niño, niña y adolescente se constituye en aquel valor especial y superior, según el cual los derechos fundamentales del niño, niña y adolescente, y en última instancia su dignidad, tienen fuerza normativa superior no sólo en el momento de la producción de normas, sino también en el momento de la interpretación de ellas, constituyéndose por tanto en un principio de ineludible materialización para el Estado, la sociedad en su conjunto y la propia familia, incluidos claro está el padre, la madre o quien sea el responsable de velar por su derechos fundamentales (Sentencia del Tribunal Constitucional recaída en el Expediente N. ${ }^{\circ}$ 02132-2008-PA/TC).

\section{DERECHO A LA IDENTIDAD VERSUS CADUCIDAD}

Cabe señalar que a la actualidad se vienen suscitando conflictos relacionadas con los procesos de impugnación de paternidad. En este caso, nos referimos al supuesto padre que reconoce al niño, niña o adolescente como si 
fuera hijo suyo. No obstante, con posterioridad a ello, tome conocimiento de que en realidad no es el padre o advierta que mediante engaños de la madre u otro sujeto ha reconocido al menor como suyo. En dichos casos, corresponde iniciar un proceso de impugnación de paternidad. Sin embargo, el artículo 400 del Código Civil establece como plazo de caducidad el término de 90 días, plazo que consideramos muy corto, ya que pueden presentarse casos en que la demanda es presentada de forma posterior al plazo señalado, pudiendo la parte demandada deducir la respectiva excepción, con el objeto de lograr la improcedencia de la demanda incoada.

Si bien es cierto que se está prefiriendo el respeto al principio de seguridad jurídica para que el demandante no interponga la demandada cuando crea conveniente, esto trae consigo la vulneración del derecho constitucional de identidad del niño, niña o adolescente, así como también del derecho a la verdad.

\subsection{Casación N. ${ }^{\circ}$ 3797-2012 Arequipa}

Ahora bien, la Sala Civil Permanente de la Corte Suprema de Justicia de la República, en la Casación N. ${ }^{\circ}$ 3797-2012 Arequipa del 30 de septiembre de 2014 , en un proceso de impugnación de paternidad, declaró por mayoría infundado el recurso de casación, bajo los siguientes fundamentos:

- En el considerando noveno se señala que «el menor fue reconocido libremente por el demandante [...]. [E]l menor al momento de la presentación de la demanda tenía diecisiete años y discapacitado. $[\mathrm{N}] \mathrm{i}$ el menor ni su madre han cuestionado su identidad después del reconocimiento y que el demandante ya se había enterado de que no era el padre biológico del menor.»

- En el considerando décimo establece «[q]ue la procreación constituye el presupuesto biológico fundamental en la constitución de la relación jurídica paterno filial, sin embargo, dicha filiación otorga una identidad que, en primera instancia, podemos llamar estática, pero que luego se hará realizando en el acontecer diario de una manera dinámica y proyectiva.»

- En el considerando décimo tercero indica que «la identidad estática y dinámica aludidas en el considerando anterior no han sido cuestionadas por el menor, por lo que no se trata por tanto de solucio- 
narle el problema a él, sino más bien de crearle uno, de generarle zozobra en su vida diaria, de perturbarlo anímicamente sobre quién es y de dónde proviene.»

- Por lo que resuelve declarar Infundado el recurso de casación. A este voto se adhieren los magistrados, Almenara Bryson, Estrella Cama, Calderón Castillo y Calderón Puertas.

Sin perjuicio de ello, la magistrada Huamaní Llamas —en su voto en discordia- señala que:

- En el considerando tercero se indica que «ante la certeza que no es el padre biológico del menor y con la aparición de la prueba de $\mathrm{ADN}$, sumado al derecho a la identidad de las personas, que es un derecho constitucional [...].»

- Señala también que el Fiscal Adjunto Supremo Civil dictamina que se declare fundada la casación.

- En el considerando décimo sostiene «que quien impugna la paternidad es el mismo reconociente, por lo que conforme a lo dispuesto por el artículo 395 del C.C el reconocimiento no admite modalidad y es irrevocable. Aparentemente no estaría legitimado para accionar; sin embargo, se precisa que el recurrente no busca revocar su manifestación de voluntad inicial, ya que la destrucción del acto no depende de su mera voluntad, sino que esta sería producto del vicio, es decir la no correspondencia con la verdad biológica. De ello se tiene que el demandante en calidad de reconociente se encuentra legitimado activamente para demandar por la impugnación de paternidad del hijo extramatrimonial, ya que el vicio que denunciado estriba en la falta de coincidencia con la verdad biológica.»

- En el considerando décimo segundo señala «que resulta primordial el interés superior del niño en conocer quiénes son sus verdaderos padres, los autores de su existencia».

- En su considerando décimo quinto indica «que no se puede dejar de administrar justicia, por la aplicación estricta de una norma meramente formalista, cuya expedición se dio válidamente en una época donde la verdad formal no admitía la existencia y el reconocimiento legal de una prueba certera, como lo es hoy la prueba de $\mathrm{ADN}$, es así que se considera en el presente caso que el artículo 400 
del C.C no sólo limita el ejercicio de los derechos contemplados en los artículos 363 y 402 del C.C sino que además colisiona con la referida disposición contenida en el artículo 8 de la Convención sobre los Derechos del Niño.»

- En el considerando décimo sexto, que se verifica, «que resulta evidente el conflicto existente entre el artículo 400 del Código Civil y el derecho fundamental a la identidad».

- En ese sentido su voto es porque se declare fundada la casación.

\subsection{Consulta Expediente N. $^{\circ}$ 3873-2014-San Martín}

Por otro lado, la Sala de Derecho Constitucional y Social Permanente en el Expediente N. ${ }^{\circ}$ 3873-2014-San Martín del 17 de marzo de 2015, elevado en consulta, resuelve lo siguiente:

Aprobar la resolución elevada en consulta, emitida por el Juzgado Mixto de Huallaga - Saposoa de la Corte Superior de Justicia de San Martín que inaplicó al caso concreto el artículo 400 del Código Civil y admitió a trámite en la vía del proceso de conocimiento la demanda sobre impugnación de paternidad.

En su fundamento 8.3 refiere que

«[e]l plazo de caducidad de impugnación de paternidad contenido en el artículo 400 del Código Civil, prima facie en un examen abstracto, tendría una finalidad constitucional, cual es, la protección y consolidación del estado de familia; sin embargo no se observa que el medio para obtener dicha finalidad en el caso concreto resulte idóneo, ya que la norma limita el derecho a la familia y a la identidad, restringiendo la determinación de la familia biológica a la que pertenece el menor, lo cual puede comprobarse de forma certera con la prueba de ADN ofrecida por el accionante; en tal sentido, la medida legislativa de acción de estado de impugnación de paternidad sujeta al plazo de caducidad de noventa días; resulta lesiva a los derechos involucrados expuestos en el fundamento sétimo de la presente sentencia, de acuerdo a las circunstancias particulares del caso, como es el derecho a la familia, el derecho a la identidad biológica y el principio del interés superior del niño; estando más bien desvinculado el medio, de conseguir el fin constitucional propuesto de protección de la familia, concluyéndose que dicho medio empleado por el legislador (materializado a través del artículo 400 precitado) no guarda una causalidad razonable, estando alejado más bien, del fin constitucional que persigue, en razón a que termina afectando derechos vinculados a la institución que debería tender a proteger, por lo que no supera el examen de idoneidad, deviniendo en inaplicable al caso concreto; careciendo de objeto el examen de necesidad y proporcionalidad en sentido estricto, de conformidad con el fundamento 6.12.» 
Sin perjuicio de lo anterior, el voto de la señora juez supremo Rodríguez Chávez es desaprobar la resolución elevada en consulta, pues considera que la inaplicación del plazo de caducidad previsto en el artículo 400 del Código Civil no solo es deficiente e irrelevante para la solución del presente caso, mientras se mantengan todavía eficaces las restricciones contenidas en los artículos 395 y 399 del mismo cuerpo legal, sino que además no existe ninguna justificación válida para dejar de lado en este caso las restricciones previstas por el legislador a las posibilidades de negación del acto de reconocimiento de hijo extramatrimonial.

\subsection{Pleno jurisdiccional nacional de familia}

Como hemos visto, tanto la Sala Civil como la Sala de Derecho Constitucional y Social adoptan criterios distintos sobre la inaplicación del artículo 400 del Código Civil. Lo mismo sucede en el resto de distritos judiciales. Es por esta razón que los jueces superiores de la especialidad se reunieron en el Pleno Jurisdiccional Nacional de Familia, realizado en la ciudad de Ica, con el fin de ponerse de acuerdo sobre la suspensión del plazo por la huelga de trabajadores del Poder Judicial, atendiendo a la aplicación o inaplicación del plazo de caducidad, conforme los siguientes supuestos:

Tema $N .^{\circ}$ 3: Supuestos que permiten declarar fundada la excepción de caducidad de la "acción" prevista en el artículo $400^{\circ}$ del C.C

¿En cuáles debe ser declarada fundada la excepción de caducidad de la acción prevista en el artículo $400^{\circ}$ del Código Civil?

Primera ponencia: Cuando no se ha identificado plenamente al progenitor biológico, la excepción de caducidad debe ser declarada fundada; de lo contrario, se estaría colocando al menor de edad en un estado de crisis filiatoria.

Segunda ponencia: No se aplica el artículo $400^{\circ}$ del Código Civil, pues se prefiere garantizar el derecho a la identidad de los menores de edad, el cual implica que estos conozcan su origen biológico. Votación: Ganadora por mayoría de votos.

Como puede apreciarse, se inaplica el artículo 400 del Código Civil bajo el fundamento de que en aras de salvaguardar el derecho a la identidad, a conocer el origen genético, biológico y al nombre de los menores de edad, el plazo de los 90 días para negar el reconocimiento debe ser inaplicado a través del control difuso constitucional. Esta solución guarda correspondencia con los avances legislativos jurisprudenciales y doctrinarios a nivel 
comparado, debido a que se señala que las pretensiones por las cuales se cuestiona el vínculo filial son imprescriptibles.

De esta forma, no es necesario que se emplace al progenitor biológico para que no se tenga en cuenta el referido plazo de caducidad, pues hacerlo significaría que el menor de edad tendrá como padre o madre a quien en realidad no desea mantener dicha posición y seguir manteniendo una relación filiatoria que no se sustente en la verdad genética y biológica.

\section{CONCLUSIONES}

- La caducidad de la impugnación de reconocimiento afecta el derecho a la identidad del menor porque impide conocer su verdad biológica.

- El fenecimiento del plazo de impugnación de reconocimiento afecta la prevalencia del derecho a la identidad porque conlleva la pérdida del derecho de acción.

- La caducidad de impugnación de reconocimiento afecta directamente el interés superior del niño.

- Resulta arbitrario que el legislador del Código Civil haya fijado un plazo tan corto de caducidad de 90 días para aquella acción, sin tener en cuenta que se violenta el derecho de defensa en juicio del padre y ello también atenta contra el derecho de identidad biológica del menor que es de jerarquía constitucional, porque se le obliga a mantener una filiación que no condice con su verdadera realidad biológica.

- Que el texto legal oculta la realidad biológica en tanto conlleva en sí que las consecuencias de la conducta de los padres se trasladen al hijo. En el caso de que caduque el plazo, se convalidará la situación familiar y el niño ya habrá adquirido una identidad familiar con relación a su vínculo paterno-materno-filial existente. El daño y las consecuencias que devienen de que la ley haya convalidado y mantenido una ficción basada en la mentira en lo que respecta a su realidad biológica.

- Por tanto, habiéndose verificado que el plazo de caducidad del artículo 400 del Código Civil debe inaplicarse o de otra forma ampliar el plazo a dos años. Pero también debe considerarse que no sólo debe defenderse con respecto al hijo, sino también en relación al padre, quien resultaría ser padre de quien no es su hijo. 


\section{BIBLIOGRAFÍA}

Corte Suprema de Justicia (2012). Sentencia casatoria $N^{\circ} 3797-2012$ Arequipa.

Dirección General de Compilación y Consulta del Orden Jurídico Nacional (2011). Derecho a la identidad como derecho humano. México D.F. Recuperado de: http://www. ordenjuridico.gob.mx/Publicaciones/Libros2011/Derecho_a_la_identidad_como_ derecho_humanoELECTRONICO.pdf.

Fernández, C. (2015) Derecho a la identidad personal. 2. ${ }^{a}$ ed. Lima: Instituto Pacífico.

Ferrer E., Martínez F. y Figueroa G. (2014). Diccionario de Derecho Procesal Constitucional y Convencional tomo II. México. Recuperado de: http://www.sitioswwweb.com/ miguel/DiccionarioII.pdf.

Hinostroza, A. (2002). Las excepciones en el proceso civil. Lima: Editorial San Marcos.

Tribunal Constitucional. Sentencia del Tribunal Constitucional recaida en el Expediente $N{ }^{\circ}{ }^{\circ}$ 02132-2008-PA/TC.

Vargas, R. (2011). El derecho a la identidad del hijo como objeto de protección de la presunción paterist est [Tesis de Maestría]. Lima: Universidad Nacional Mayor de San Marcos.

Vidal, F. (2011). Prescripción extintiva y caducidad. Lima: Idemsa. 